\title{
ESTETOSCÓPIO: INSTRUMENTO DE DIAGNÓSTICO E DE PROPAGAÇÃO MICROBIANA?
}

Jaciara Aparecida Dias Santos

Discente do curso de Medicina da Universidade Estadual de Montes Claros (UNIMONTES), Brasil.

E-mail: jaciarapds@gmail.com
RESUMO: O presente artigo teve por objetivo conhecer o potencial de contaminação e disseminação de estetoscópios para infecções relacionadas a serviços de saúde à luz da literatura. A fonte de busca foi a Biblioteca Virtual de Saúde, nas bases de dados Medline, Lilacs e SciELO; a coleta de dados foi realizada no mês de fevereiro de 2015, referente aos anos de 2004 a 2014. Utilizou-se os seguintes critérios de inclusão: teses e periódicos escritos em língua inglesa, espanhola e portuguesa e acessados em texto completo sobre o tema. Foram incluídos nessa revisão 14 artigos. A presença de contaminação e a possível disseminação de microrganismos pelos estetoscópios foram descritas por todos os estudos analisados. Dessa forma, foi possível identificar que o tema merece maior atenção, já que os estetoscópios podem atuar como vetores para as infecções nosocomiais.

PALAVRAS-CHAVE: Contaminação Biológica; Contaminação de Equipamentos; Estetoscópio; Infecções Nosocomiais; Profissionais da Saúde.

\section{THE STETHOSCOPE: IS IT AN INSTRUMENT FOR DIAGNOSIS OR FOR MICROBIAL DISSEMINATION?}

\begin{abstract}
The contamination and dissemination capacity of infections by stethoscopes reported in the literature is analyzed. The Virtual Health Library and databases of Medline, Lilacs and SciELO were used during February 2015 for the $2004-2014$ period. The following inclusion criteria were employed: theses and journals in English, Spanish and Portuguese accessed in full text online. Fourteen articles were included where contamination and possible dissemination of microorganisms by stethoscopes were described. The theme requires deeper attention since stethoscopes may be vectors of hospital infections.
\end{abstract}

KEY WORDS: Contamination of Equipments; Stethoscope; Biological Contamination; Health Professionals; Hospital Infections.

\section{INTRODUÇÃo}

Muitos fatores corroboram para o risco de transmissão microbiana em serviços de saúde, incluindo condições inerentes ao paciente, utilização de procedimentos invasivos, bem como exposição a fontes ambientais como, por exemplo, as mãos dos trabalhadores de saúde e os instrumentos utilizados por eles para a própria proteção e diagnóstico (FERREIRA et al., 2013; APONTE; MARTÍNEZ, 2010). 
Diferentes materiais podem estar contaminados por patógenos, dentre eles, o estetoscópio se destaca com grande importância, uma vez que seu uso é generalizado e este pode atuar como fonte de disseminação de qualquer tipo de microrganismo patogênico (DANTAS et al., 2014; FERREIRA et al., 2013).

O estetoscópio é um instrumento utilizado de forma rotineira, principalmente por médicos e enfermeiros. Esse aparelho entra em contato direto com inúmeros pacientes e, dessa forma, pode servir como veículo de disseminação de infecções nosocomiais pela transferência de microrganismos entre usuários dos serviços de saúde por intermédio dos profissionais. Apesar de ser um dos instrumentos de auxílio diagnóstico mais utilizado durante a assistência, pouca atenção tem sido atribuída aos cuidados básicos no seu manuseio, principalmente no que se refere à sua limpeza e desinfecção (DUTRA et al., 2013; LONGTIN; SCHENEIDER; TSCHOPP, 2014).

Segundo "o Ministério da Saúde: os artigos destinados ao contato da pele íntegra do paciente são chamados de artigos não críticos e requerem limpeza ou desinfecção de baixo ou médio nível, dependendo do uso a que se destinam", tal publicação não se tornou uma prática generalizada (DUTRA, 2012, p. 10). Assim, a higienização regular, com solução alcoólica a $70 \%$, é um procedimento simples, rápido e eficaz, necessitando ser realizada de preferência após o contato com cada paciente, principalmente às áreas que entram em contato com a pele do usuário (ANGERAMI; MENDES, 1975; KURTZ et al., 2009; WHITTINGTON et al., 2009).

Nessa perspectiva, o presente estudo justificase pela necessidade de uma reflexão acerca do potencial de contaminação e disseminação de microorganismos pelos estetoscópios, uma vez que são instrumentos de trabalho multiprofissional, que entram em contato direto com a pele dos pacientes. Dessa forma, este estudo tem como objetivo conhecer o potencial de contaminação e disseminação de estetoscópios para infecções relacionadas a serviços de saúde à luz da literatura.

Vale ressaltar que o estudo poderá contribuir para que o público acadêmico e profissionais da saúde possam encontrar nessa pesquisa uma síntese de estudos atuais e significativos no meio científico determinantes para o entendimento e prevenção da possível contaminação e disseminação microbiana por estetoscópios.

\section{METODOLOGIA}

Esta investigação delineou-se a partir de uma revisão integrativa da literatura científica que tem por objetivo agrupar, avaliar e sintetizar o resultado de pesquisas sobre um determinado assunto, de forma organizada e sistemática, sendo utilizada para uma compreensão mais abrangente dos estudos a respeito do tema proposto, funcionando como ferramenta de síntese de trabalhos publicados e consagrados cientificamente (MARTINATO et al., 2010).

A pesquisa foi realizada no mês de fevereiro de 2015. Para o levantamento bibliográfico foram utilizadas bases de dados científicas, buscou-se para o estudo publicações científicas brasileiras e estrangeiras, na Biblioteca Virtual de Saúde (BVS), indexadas nas bases de dados LILACS (Literatura Latino-Americana e do Caribe em Ciências da Saúde) SCIELO (Scientific Eletronic Library Online) e MEDLINE (Medical Literature Analysis and Retrieval System On-Line), com os seguintes descritores: "contaminação de equipamentos", "estetoscópio", "contaminação biológica", "profissionais da saúde" e "infecções nosocomiais", procurando assim ampliar ao máximo o resultado da busca.

Foi realizado um recorte temporal dos artigos publicados de 2004 a 2014. Inicialmente, baseouse nos títulos e resumos para análise dos artigos. Utilizou-se os seguintes critérios de inclusão: teses e periódicos indexados publicados em revistas nacionais e internacionais; escritos em língua inglesa, espanhola e portuguesa; acessados em texto completo. Foram excluídos artigos não relacionados à temática.

A partir da estratégia definida, a busca bibliográfica resultou em 55 artigos, sendo que 14 foram selecionados. Destes, 05 foram artigos em inglês, $04 \mathrm{em}$ espanhol e 05 em português. Todos os estudos foram lidos criteriosamente em sua íntegra e selecionados por atenderem rigorosamente aos critérios de inclusão, e seus conteúdos foram julgados suficientemente esclarecedores e pertinentes para fazerem parte do presente estudo.

\section{RESULTADOS}

Para fazer parte desta revisão integrativa foram selecionados 13 artigos. Com o intuito de facilitar a análise e apresentação de dados foi elaborado o quadro 1, onde são apresentados dados sobre título do artigo, ano e objetivos de cada estudo. 
Quadro 1. Distribuição dos Artigos Selecionados, Segundo Título, Ano e Objetivo da Publicação, 2004-2014

\begin{tabular}{|c|c|c|c|}
\hline $\mathbf{N}^{\mathbf{o}}$ & Título & Ano & Objetivo da Publicação \\
\hline 1 & Bacterial Contamination of Stethoscopes & 2014 & $\begin{array}{l}\text { Determinar o nível de contaminação dos estetoscópios e analisar } \\
\text { os métodos de desinfecção utilizados pelos estagiários e pós- } \\
\text { graduados de um hospital universitário no sul da Índia. }\end{array}$ \\
\hline 2 & $\begin{array}{l}\text { Staphylococcus aureus } \\
\text { isolados de estetoscópio hospitalar }\end{array}$ & 2014 & $\begin{array}{l}\text { Avaliar a prevalência de Staphylococcus aureus } \text { (S. aureus) no } \\
\text { diafragma dos estetoscópios e determinar o perfil de resistência } \\
\text { do microrganismo frente a diferentes antibióticos. }\end{array}$ \\
\hline 3 & $\begin{array}{l}\text { Contamination of stethoscopes and physicians } \\
\text { hands after a physical examination }\end{array}$ & 2014 & $\begin{array}{l}\text { Comparar o nível de contaminação das mãos dos médicos e } \\
\text { estetoscópios e explorar o risco de transmissão cruzada de } \\
\text { microrganismos através da utilização de estetoscópios. }\end{array}$ \\
\hline 4 & $\begin{array}{l}\text { Prevalência de contaminação bacteriana em } \\
\text { estetoscópios }\end{array}$ & 2013 & $\begin{array}{l}\text { Avaliar a prevalência de contaminação bacteriana no diafragma } \\
\text { dos estetoscópios em diferentes unidades de atendimento de } \\
\text { saúde do município de Santa Cruz do Sul (RS), bem como as } \\
\text { práticas de limpeza utilizadas pelos usuários de estetoscópio e } \\
\text { o grau de informação dos profissionais da área da saúde com } \\
\text { respeito às recomendações de limpeza desse instrumento. }\end{array}$ \\
\hline 5 & $\begin{array}{l}\text { Frecuencia de bactérias en estetoscópios Del } \\
\text { personal de salud y su patron de resistencia. } \\
\text { departamento de emergencias. Complejo } \\
\text { hospitalario universitario "Ruiz y Páez". Ciudad } \\
\text { Bolivar. Estado Bolivar }\end{array}$ & 2010 & $\begin{array}{l}\text { Determinar a frequência de bactéria em estetoscópios de } \\
\text { profissionais da saúde e seu patrão de resistência do Departamento } \\
\text { de Emergências do Complexo Hospitalar Universitário "Ruiz y } \\
\text { Páez". }\end{array}$ \\
\hline 6 & $\begin{array}{l}\text { Determinación de micro-organismos en } \\
\text { estetoscopios de médicos e internos en el hospital } \\
\text { de Santo Domingo. }\end{array}$ & 2009 & $\begin{array}{l}\text { Comprovar a presença de microrganismos com potencial } \\
\text { patogênico nos estetoscópios dos médicos do hospital Doctor } \\
\text { Francisco e Moscoso Puello. }\end{array}$ \\
\hline 7 & $\begin{array}{l}\text { Micro-organismos presentes en fonendoscopios, } \\
\text { manos, cavidad oral y nasal de estudiantes de una } \\
\text { facultad de medicina. }\end{array}$ & 2012 & $\begin{array}{l}\text { Estabelecer a frequência dos microrganismos isolados em } \\
\text { estudantes de uma Faculdade de Medicina. }\end{array}$ \\
\hline 8 & $\begin{array}{l}\text { Bacterial contamination of stethoscopes on the } \\
\text { intensive care unit }\end{array}$ & 2009 & $\begin{array}{l}\text { Avaliar quantas vezes estetoscópios de cabeceira em uma } \\
\text { unidade de terapia intensiva foram limpos e se eles se tornaram } \\
\text { colonizados com bactérias potencialmente patogênicas. }\end{array}$ \\
\hline 9 & $\begin{array}{l}\text { Contaminação bacteriana de estetoscópios das } \\
\text { unidades de pediatria em um hospital universitário }\end{array}$ & 2009 & $\begin{array}{l}\text { Avaliar a contaminação de estetoscópios utilizados em setores } \\
\text { pediátricos de hospital universitário. }\end{array}$ \\
\hline 10 & $\begin{array}{l}\text { Estetoscopio, bata y corbata, y el riesgo de } \\
\text { infecciones nosocomiales }\end{array}$ & 2011 & $\begin{array}{l}\text { Avaliar se jaleco, gravata e estetoscópio são vetores importantes } \\
\text { para a transmissão de infecções nosocomiais. }\end{array}$ \\
\hline 11 & $\begin{array}{l}\text { Bacterial contamination of stethoscopes used by } \\
\text { health workers: public health implications }\end{array}$ & 2010 & $\begin{array}{l}\text { Avaliar tanto o potencial de transmissão bacteriana por } \\
\text { estetoscópios usados pelos profissionais de saúde na Nigéria e as } \\
\text { implicações para a segurança e controle de infecções hospitalares. }\end{array}$ \\
\hline 12 & $\begin{array}{l}\text { Superfícies do ambiente hospitalar: um possível } \\
\text { reservatório de micro-organismos subestimado? } \\
\text { Revisão integrativa }\end{array}$ & 2013 & $\begin{array}{l}\text { Caracterizar e descrever pesquisas brasileiras acerca da } \\
\text { contaminação de superfícies em ambiente hospitalar. }\end{array}$ \\
\hline 13 & $\begin{array}{l}\text { Estetoscópio: uma ferramenta para diagnóstico e } \\
\text { de disseminação de bactérias resistentes? }\end{array}$ & 2009 & $\begin{array}{l}\text { Avaliar o potencial de contaminação de diafragma dos } \\
\text { estetoscópios, de todas as unidades de atendimento do Hospital } \\
\text { Santa Cruz. }\end{array}$ \\
\hline 14 & $\begin{array}{l}\text { Avaliação da prevalência de contaminação } \\
\text { bacteriana de estetoscópios usados por } \\
\text { profissionais de saúde em diferentes unidades de } \\
\text { atendimento, município de Santa Cruz do Sul, RS, } \\
\text { Brasil. }\end{array}$ & 2012 & $\begin{array}{l}\text { Avaliar a prevalência de contaminação bacteriana no diafragma } \\
\text { dos estetoscópios em diferentes unidades de atendimento do } \\
\text { Hospital Santa Cruz (HSC), Serviço de Atendimento Móvel de } \\
\text { Urgência (SAMU) e unidades de Atenção Primária em saúde, do } \\
\text { município de Santa Cruz do Sul (RS), Brasil. }\end{array}$ \\
\hline
\end{tabular}

Fonte: Dados da pesquisa. 
$\mathrm{Na}$ análise dos artigos selecionados, observouse que o período com a maior quantidade de publicações foi o ano de 2009 com 04 (28,6\%) artigos, seguido por 2014 com 03 (21,4\%). Já os anos de 2010, 2012 e 2013 apresentaram $02(14,3 \%)$ publicações cada. $\mathrm{O}$ ano de 2011 apresentou 01 (7,1\%) estudo. Dessa forma, observase que houve um decréscimo no número de publicações nos últimos anos, evidenciando uma possível diminuição da preocupação com o problema em questão. Avaliando as áreas do conhecimento, foram contempladas quatro áreas conforme informações apresentadas na Tabela 1 .

Tabela 1. Distribuição do Número de Pesquisas, Segundo as Áreas do Conhecimento, 2004-2014

\begin{tabular}{lcc}
\hline $\begin{array}{l}\text { Área do } \\
\text { conhecimento }\end{array}$ & $\mathbf{N}$ & $\%$ \\
\hline Medicina & 9 & 64,3 \\
Biomedicina & 3 & 21,4 \\
Enfermagem & 1 & 7,1 \\
Biologia & 1 & 7,1 \\
\hline Total & $\mathbf{1 4}$ & $\mathbf{1 0 0}$ \\
\hline
\end{tabular}

Fonte: Dados da pesquisa.

De acordo com a análise dos estudos a área do conhecimento com o maior número de pesquisas foi a Medicina, contabilizando 08 (64,3\%) estudos. Pode-se inferir que as demais categorias profissionais necessitam explorar mais a temática, já que são áreas que utilizam o estetoscópio como ferramenta de trabalho.

Verificando as publicações de acordo com o país de origem pode-se perceber que foram realizados 06 (42,85\%) estudos no Brasil, já os demais obtiveram apenas $01(7,14 \%)$ artigo (Tabela 2).

Tabela 2. País de Origem das Publicações, 2004-2014

\begin{tabular}{lcc} 
& & (continua) \\
\hline País de origem & N & $\%$ \\
\hline Brasil & 6 & 42,85 \\
México & 1 & 7,14 \\
Nigéria & 1 & 7,14 \\
Bolívia & 1 & 7,14 \\
Colômbia & 1 & 7,14 \\
Inglaterra & 1 & 7,14
\end{tabular}

(conclusão)

\begin{tabular}{lcc} 
Suíça & 1 & 7,14 \\
Índia & 1 & 7,14 \\
$\begin{array}{l}\text { República } \\
\text { Dominicana }\end{array}$ & 1 & 7,14 \\
\hline Total & $\mathbf{1 4}$ & $\mathbf{1 0 0}$ \\
\hline
\end{tabular}

Fonte: Dados da pesquisa.

Outro aspecto analisado nos artigos foi com relação à existência de contaminação nos estetoscópios (Tabela 3).

Tabela 3. Distribuição da Existência de Contaminação nos Estetoscópios Analisados nos Estudos, 2004-2014

\begin{tabular}{lll}
\hline Contaminação & N & $\%$ \\
\hline Presença & 14 & 100 \\
Ausência & 0 & 0 \\
\hline Total & 14 & 100 \\
\hline
\end{tabular}

Fonte: Dados da pesquisa.

Assim, conforme a tabela foi possível observar que todas as publicações selecionadas apresentaram dados sobre contaminação nos estetoscópios pesquisados. Os microrganismos encontrados nos estetoscópios contaminados também foram alvo desta investigação (Tabela 4).

Tabela 4. Distribuição dos Principais Microrganismos Isolados, 2004-2014

\begin{tabular}{lcc}
\hline Microrganismos & $\mathbf{N}$ & $\%$ \\
\hline $\begin{array}{l}\text { Staphylococcus } \\
\text { aureus }\end{array}$ & 14 & 100 \\
$\begin{array}{l}\text { Escherichia coli } \\
\text { Staphylococcus } \\
\text { coagulase negativa }\end{array}$ & 13 & 92,8 \\
$\begin{array}{l}\text { Pseudomonas } \\
\text { aeruginosa }\end{array}$ & 14 & 100 \\
$\begin{array}{l}\text { Staphylococcus } \\
\text { epidermidis }\end{array}$ & 12 & 85,7 \\
Fungos, leveduras & 2 & 92,8 \\
\hline
\end{tabular}

Fonte: Dados da pesquisa.

$\mathrm{O}$ resultado da análise demonstrou que a maioria dos microrganismos eram bactérias, sendo que a Staphylococcus aureus e a Staphylococcus coagulase 
negativa foram as bactérias encontradas em todos os estudos 14 (100\%). O cenário do estudo também foi analisado nesta pesquisa (Tabela 5).

Tabela 5. Distribuição dos Cenários Analisados nos Estudos, 2004-2014

\begin{tabular}{lcc}
\hline Cenário de estudo & N & $\%$ \\
\hline Hospital & 11 & 78,58 \\
$\begin{array}{l}\text { Estratégia de Saúde } \\
\text { da Família (ESF) }\end{array}$ & 0 & 0 \\
$\begin{array}{l}\text { Serviço de } \\
\text { Atendimento } \\
\text { Móvel de Urgência } \\
\text { (SAMU) }\end{array}$ & 0 & \\
$\begin{array}{l}\text { Hospital, ESF e } \\
\text { SAMU }\end{array}$ & 2 & 0 \\
Não especificado & 1 & 14,28 \\
\hline Total & $\mathbf{1 4}$ & 7,14 \\
\hline
\end{tabular}

Fonte: Dados da pesquisa.

Assim, foi possível perceber que os estudos foram predominantes em ambiente hospitalar com 11 (78,58\%) publicações. Desse modo, torna-se necessário que outros âmbitos de saúde também sejam pesquisados quanto à contaminação dos estetoscópios utilizados pelos profissionais.

\section{DISCUSSÃO}

O estetoscópio é um instrumento ao qual não se confere a devida relevância, embora haja estudos que comprovem sua contaminação e seu papel como transmissor de microrganismos.

"A transmissão de infecções por meio de dispositivos médicos contaminados já tem sido demonstrada em instrumentos como termômetros, medidores de pressão arterial, estetoscópios, luvas, máscaras, canetas, crachás e jalecos" (DUTRA et al., 2013, p. 156).

A partir da década de 90, principalmente após as pesquisas de Jones e Wrigth, estudos evidenciaram que os estetoscópios podem servir de meio para a disseminação de estafilococos e estreptococos (DUTRA et al., 2013; UNEKE et al., 2010).
Vale salientar que, de acordo com o Ministério da Saúde, infecção hospitalar (IH) ou nosocomial é aquela adquirida após a admissão do paciente e que se revela durante a internação, ou após a alta, quando estiver relacionada com a internação ou procedimentos hospitalares. O diagnóstico da infecção hospitalar ocorre quando, na mesma topografia em que foi diagnosticada infecção comunitária (é a infecção constatada ou em incubação no ato da admissão do paciente, desde que não relacionada com a internação anterior no mesmo hospital), for isolado um microrganismo diferente, acompanhado da piora das condições clínicas do usuário; ou se ignorar o período de incubação do germe, não houver evidência clínica e/ou dados laboratoriais de infecção no instante da internação e se revelar a partir de 72 horas após a admissão; relacionadas a procedimentos diagnósticos e/ou terapêuticos. Os usuários provenientes de outro hospital que se internam com infecção são tidos como portadores de IH do hospital de origem e tal evento deve ser notificado ao hospital (PADRÃO et al., 2010; BARDAQUIM, 2011).

Ademais, os estudos incluídos na presente pesquisa foram realizados em hospitais, SAMU e ESF, sendo aquele predominante. No estudo de Xavier e Ueno (2009), realizado em um hospital de Taubaté (SP), foram analisados 38 estetoscópios, sendo que 33 (86,8\%) estavam contaminados. Além disso, os estetoscópios utilizados no Pronto Socorro apresentaram maior nível de contaminação e o microrganismo, comumente, isolado foi o Staphylococcus coagulase negativo.

A pesquisa desenvolvida no hospital em Sorocaba (SP) evidenciou que dos 300 estetoscópios pesquisados, $87 \%$ estavam contaminados e foram isolados os seguintes microrganismos: Staphylococcus aureus, o Staphylococcus coagulase negativo, leveduras, Sarcina, Bacillus sp, Streptococcus sp, Acinetobacter sp, Pseudomonas putida e Klebsiella pneumoniae (MALUF et al., 2002).

Em análise de 25 estetoscópios, provenientes do Hospital Santa Cruz (RS), observou-se que houve contaminação em 92\% dos aparelhos. Isolou-se cocos gram-positivos, leveduras, fungos, bacilos gram-positivos e gram-negativos. E dos microrganismos identificados, $60 \%$ eram bactérias do gênero Staphylococcus, deste 
percentual $87 \%$ eram coagulase negativo (KURTZ et al., 2009).

Dos 32 estetoscópios avaliados, pertencentes ao hospital público de Maceió (AL), 13 (41\%) estavam contaminados com S. aureus e 56\% com outros microrganismos. Após a higienização com etanol 70\%, a contaminação não foi mais evidenciada (DANTAS et al., 2014).

Em estudo conduzido em dois hospitais públicos e um privado de Mangarole, na Índia, foi possível demonstrar que, de um total de 105 estetoscópios examinados, 93 (88,6\%) estavam contaminados. Dentre os microrganismos isolados incluíam-se Staphylococcus coagulase-negativo (56,1\%), Staphylococcus aureus $(18,1 \%)$, Staphylococcus aureus resistente à meticilina (MRSA) (4,7\%), Pseudomonas aeruginosa (6,6\%), Escherichia coli (2,8\%), Klebsiella spp (1,9\%), Bacillus spp (8,5\%) e Micrococcus spp (1,9\%) (ASWIN; HEGDE, 2014).

"Staphylococcus aureus é uma das espécies do gêneroStaphylococcusspp, produtoradecoagulase, sendo responsável por mais de 30\% das infecções hospitalares e apresenta uma gama de fatores de virulência" (MARTINS, 2012, p. 4). "Os Staphylococcus aureus, resistente à meticilina (MRSA), presente na microbiota transitória das mãos dos profissionais de saúde, também podem ser isolados em maçanetas, assentos sanitários, teclados de computador e no diafragma do estetoscópio" (OLIVEIRA; DAMASCENO, 2012, p. 29).

A pesquisa desenvolvida em um hospital do México evidenciou que $85,7 \%$ dos estetoscópios estavam contaminados. Dentre os microrganismos isolados, os Staphylococcus foram as bactérias contaminantes mais comuns (47,5\%), também houve isolamento de MRSA (32\%) e em $21 \%$ dos casos ocorreu crescimento de estafilococos coagulase negativo (BAPTISTA-GONZÁLEZ; ZAMORANO-JIMÉNEZ, 2011).

Já o estudo no hospital de Santo Domingo, na República Dominicana, demonstrou que dos 63 estetoscópios estudados, 92 cepas bacterianas foram isoladas: Staphylococcus epidermidis (36 cepas), Staphylococcus aureus (27 cepas), Serratia Iicuefaciens (10 cepas), bacilos Gram positivos (8 linhagens), Serratia rubidaea (3 amostras), Escherichia coli (2 linhagens),
Providencia rettgeri (2 linhagens), Pseudomonas aeruginosa (2 amostras), Alcalifaciens providência (1 cepa) e Crycrescens kluyueya (1 estirpe) (TERRERO et al., 2009).

Foram avaliados 81 estetoscópios utilizados por profissionais de saúde em distintas unidades de saúde em Santa Cruz do Sul (RS), SAMU, ESF e hospitais, sendo que $96,2 \%$ estavam contaminados, destacando Staphylococcus aureus como o microrganismo comumente encontrado (DUTRA et al., 2013).

A presença de gram-negativas e gram-positivas nos estetoscópios pode estar associada à falta de lavagem das mãos pelos profissionais da saúde, ausência ou higienização inadequada do aparelho após a utilização durante o exame físico do paciente. Estudos demonstram que a higienização dos estetoscópios reduz até $96,3 \%$ dos microrganismos resistentes, como MRSA (RODRIGUEZ et al., 2012; OLIVEIRA et al., 2013; KURTZ et al., 2009).

A lavagem frequente das mãos é a intervenção mais relevante no controle da infecção. Ademais, a desinfecção de instrumentos não críticos, como o estetoscópio, precisa fazer parte do conhecimento curricular da graduação e pós-graduação de profissionais que utilizam esse aparelho (MELO et al., 2009; DUTRA, 2012).

\section{CONCLUSÃo}

Com base na análise das publicações evidenciou-se a existência de estetoscópios altamente contaminados. Além disso, estudos apontaram a presença de microrganismos resistentes, como Staphylococcus aureus resistente à meticilina (MRSA), outro fator importante verificado nesta pesquisa está relacionado com o cenário de estudo, sendo que poucas pesquisas foram desenvolvidas na Estratégia Saúde da Saúde e no Serviço de Atendimento Móvel de Urgência, o âmbito hospitalar foi o foco. Vale lembrar, ainda, que a temática em questão foi explorada por poucas publicações.

Ressalta-se, então, a relevância da correta lavagem das mãos e a adequada desinfecção desses aparelhos com o uso de solução asséptica após o contato com cada paciente. Dessa forma, a utilização de tais 
medidas pelos profissionais acarretará uma diminuição significativa da contaminação e da possível disseminação de microrganismos pelos estetoscópios, funcionando como vetor para as infecções nosocomiais, para isso é imprescindível que as instituições de ensino e saúde intensifiquem as informações acerca da importância da limpeza dos instrumentos viabilizando, assim, uma melhoria nas condições assistenciais e de saúde das pessoas. Com isso, espera-se poder contribuir para embasar outros trabalhos sobre a contaminação de estetoscópios.

\section{REFERÊNCIAS}

ANGERAMI, E. L. S.; MENDES, I. A. C. Estudobacteriológico das úvulas de estetoscópios. Rev Bras Enf., v. 28, n. 1, p. 77-80, 1975.

APONTE, R. V. F.; MARTÍNEZ, J. M. Z. Frecuencia de bactérias em estetoscópios del personal de salud y supatron de resistencia. 2010. 59f. Tese (Graduação) - Escola de Ciências da Saúde, Universidade OrienteNúcleo Bolívar, Cidade Bolivar, Bolívia.

ASWIN, R. S.; HEGDE, A. Bacterial Contamination of Stethoscopes. Int J Scie Res., v. 3, n. 11, p. 406-408, 2012.

BAPTISTA-GONZÁLEZ, H. A.; ZAMORANO-JIMÉNEZ, C. A. Estetoscopio, bata y corbata, y elriesgo de infecciones nosocomiales. Rev Invest Med Sur Mex., v. 18, n. 4, p. 195-202, 2011.

BARDAQUIM, V. A. Incidência microbiana e medidas preventivas de contaminação em superfícies de um centro cirúrgico. 2011, 71f. Tese (Mestrado) - Campos de São Carlos, Universidade Federal de São Carlos, São Carlos, SP.

DANTAS, A. V. S.; VIEIRA, L. A. O.; AMORIN, A. V. O.; SANTOS, M. S.; SOUZA, E. C.; SOUZA, L. I. O.; FIDELIS, T. A. A.; SOUZA, V. P.; LIMA, G. M. S. Staphylococcus aureus resistentes à meticilina isolados de estetoscópio hospitalar. J Health Sci Inst., v. 32, n. 2, p. 145-147, 2014.
DUTRA, L. G. B. Avaliação da prevalência de contaminação bacteriana de estetoscópios usados por profissionais de saúde em diferentes unidades de atendimento, município de Santa Cruz do Sul, RS, Brasil. 2012, 80f. Tese (Mestrado) - Universidade de Santa Cruz do Sul (UNISC), Santa Cruz do Sul, RS.

DUTRA, L. G. B.; NETO, H. B. N.; NEDEL, F. B.; LOBO, E. A. Prevalência de contaminação bacteriana em estetoscópios. Rev Inst Adolfo Lutz., v. 72, n. 2, p. 15560, 2013.

FERREIRA, A. M.; BARCELOS, L. S.; RIGOTTI, M. A.; ANDRADE, D.; ANDREOTTI, J. T.; ALMEIDA, M. G. Superfícies do ambiente hospitalar: um possível reservatório de micro-organismos subestimado? Revisão integrativa. Rev Enferm UFPE., v. 7, n. (esp.), p. 417182, 2013.

KURTZ, A. C. N.; RUTZEN, W.; KRUMMENAUER, E. C.; RENNER, J. D. P.; CARNEIRO, M. Estetoscópio: uma ferramenta para diagnóstico e de disseminação de bactérias resistentes? Rev da AMRIGS., v. 53, n. 3, p. 319, 2009.

LONGTIN, Y.; SCHENEIDER, A.; TSCHOPP, C. Contamination of stethoscopes and physicians hands after a physical examination. Mayo Clinic., v. 89, n. 3, p. 291-299, 2014

MALUF, M. E. Z.; MALDONADO, A. F.; BERCIAL, M. E.; PEDROSO, S. A. Stethoscope: a friend or an enemy? Rev Paul Med., v. 120, n. 1, p. 13-5, 2002.

MARTINATO, M. C. N. B.; SEVERO, D. F.; MARCHAND, E. A. A.; SIQUEIRA, HEDI C. H. Absenteísmo na enfermagem: uma revisão integrativa. Rev Gaúcha Enferm., v. 31, n. 1, p. 160-6, 2010.

MELO, L. L. S.; LIMA, A. M. C.; DAMASCENO, C. A. V.; VIEIRA, A. L. P. Flora fúngica no ambiente da Unidade de Terapia Intensiva Pediátrica e Neonatal em hospital terciário. Rev Paul Pediatr., v. 27, n. 3, p. 303-8, 2009.

OLIVEIRA, A. C.; DAMASCENO, Q. S. O papel do ambiente hospitalar na disseminação de bactérias resistentes. Rev Epidemiol Control Infect., v. 2, n. 1, p. 28-31, 2012. 
OLIVEIRA, A. C.; GONZAGA, C.; COSTA, R.; DAMACENO, Q. S.; GARBACCIO, J. L. Desafios e perspectivas para a contenção da resistência bacteriana na óptica dos profissionais de saúde. Rev Eletr Enf., v. 15, n. 3, p. 747 54, 2013.

PADRÃO, M. C.; MONTEIRO, M. L.; MACIEL, N. R.; VIANA, F. F. C. F.; FREITAS, N. A. Prevalência de infecções hospitalares em unidade de terapia intensiva. Rev Bras Clin Med., v. 8, n. 2, p. 125-8, 2010.

RODRIGUEZ, I. A. M.; CALIXTO, O. J.; BECERRA, W. A.; VÁSQUEZ, J. F.; BRAVO, J. S.; PACHÓN, D. P. Microorganismos presentes en fonendoscopios, manos, cavidad oral y nasal de estudiantes de una facultad de medicina. Rev Fac Med., v. 20, n. 1, p. 90-100, 2012.

TERRERO, E.; DÍAZ, M.; MERCEDES, A.; DISLA, M.; BELTRÉ, V. Determinación de microorganismos en estetoscopios de médicos e internos em el hospital de Santo Domingo. Rev Ciencias de la salud, v. 6, n. 1, p. 23-29, 2009.

UNEKE, C. J.; OGBONNA, A.; OYIBO, P. G.; ONU, C. M. Bacterial contamination of stethoscopes used by health workers: public health implications. J Infect. Dev. Ctries., v. 4, n. 7, p. 436-441, 2010.

XAVIER, M. S.; UENO, M. Contaminação bacteriana de estetoscópios das unidades de pediatria em um hospital universitário. Rev Soc Bras Med Tropical, v. 42, n. 2, p. 217-218, 2009.

WHITTINGTON, A. M.; WHITLOW, G.; HEWSON, D.; THOMAS, C.; BRETT, S. J. Bacterial contamination of stethoscopes on the intensive care unit. Anaesthesia, v. 64, p. 620-624, 2009.

Recebido em: 19 de fevereiro de 2015 Aceito em: 29 de setembro de 2015 